\title{
Corrigendum: Grb2 monomer-dimer equilibrium determines normal versus oncogenic function
}

Zamal Ahmed, Zahra Timsah, Kin M. Suen, Nathan P. Cook, Gilbert R. Lee IV, Chi-Chuan Lin, Mihai Gagea, Angel A. Marti \& John E. Ladbury

Nature Communications 6:7354 doi: 10.1038/ncomms8354 (2015); Published 24 Jun 2015; Updated 3 Aug 2015.

In this Article, there are errors in the labelling of the $y$ axes in Figs 2 and 3. In both figures, 'Fluorescence intensity' should read 'Number of pixels'. The correct versions of these figures appear below.

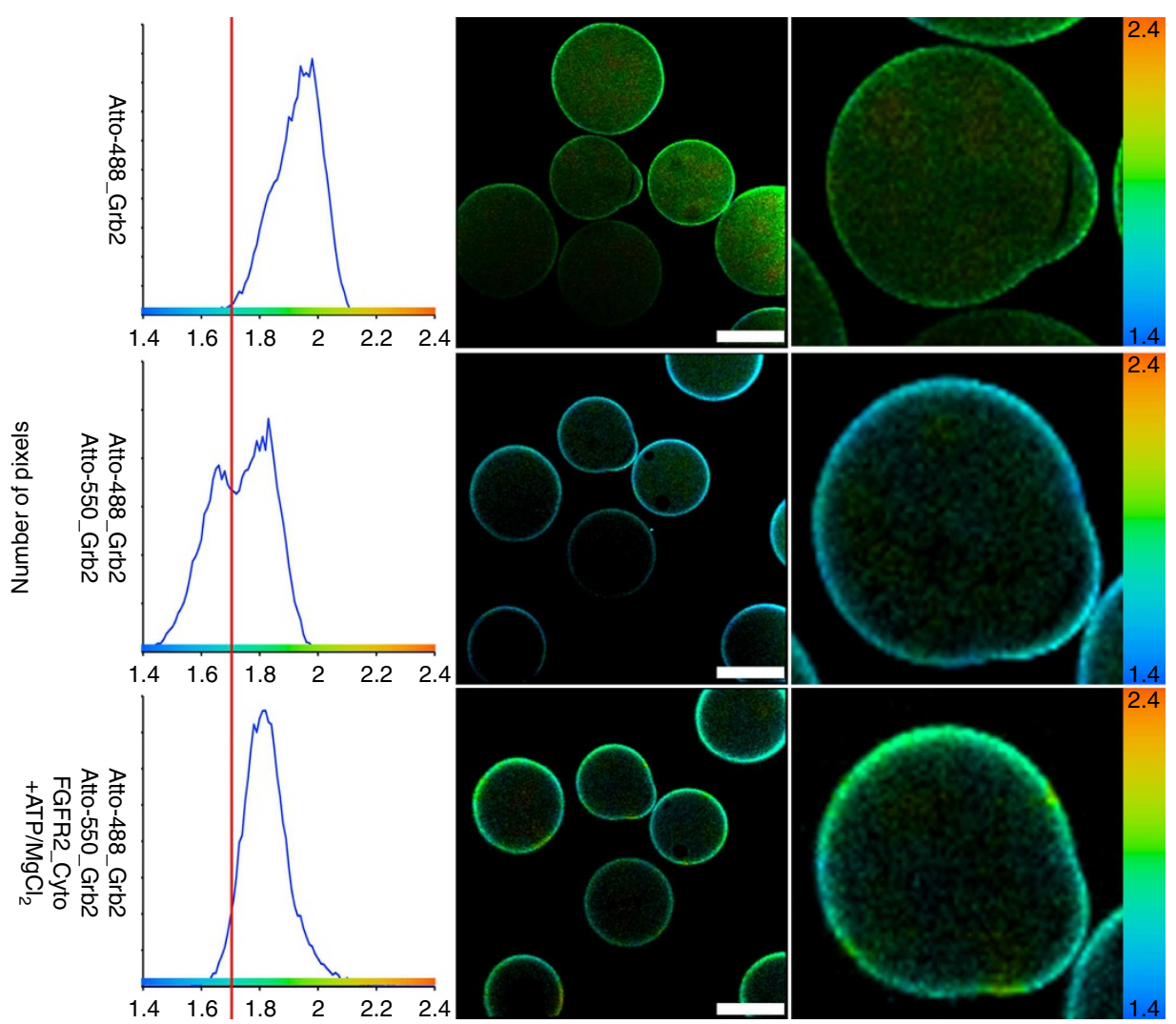

Figure 2 


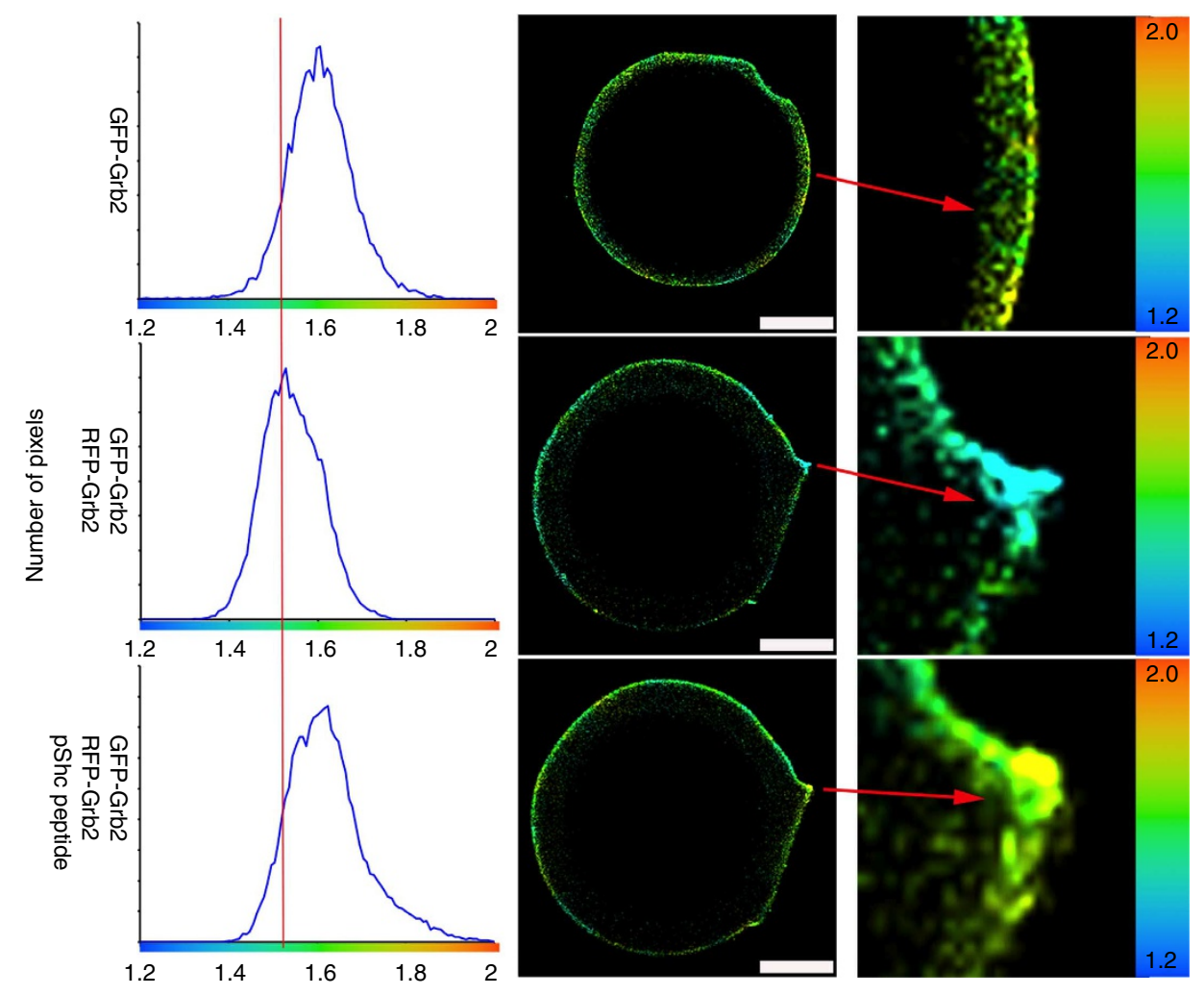

Figure 3 